\title{
Preparation, Surface Acidity and Catalytic Esterification Activity of Solid Acid $\mathrm{S}_{2} \mathrm{O}_{8}^{2-} / \mathrm{TiO}_{2}-\mathrm{La}_{2} \mathrm{O}_{3}$ \\ Jie-Yu HE ${ }^{1, a,{ }^{*}}$, Hui WANG ${ }^{1, b}$,De-Zhong LIAO ${ }^{2, c}$ and Yun-Kang JIN $^{1, d}$ \\ ${ }^{1}$ College of Marine Science \& Technology, Hainan Tropical Ocean University, Sanya 572022, China; \\ ${ }^{2}$ College of Chemistry \& Chemical Engineering, Hunan Institute of Science and Technology, Yueyang 414000, China \\ ajyhe555@163.com, bhwan072@163.com, Cdz.liao@163.com, d410421958@qq.com
}

Keywords: Solid acid, Titanium sulfate, Lanthanum oxide, Acid properties, Catalytic esterification

\begin{abstract}
Solid acid $\mathrm{S}_{2} \mathrm{O}_{8}^{2-} / \mathrm{TiO}_{2}-\mathrm{La}_{2} \mathrm{O}_{3}$ (STL) was prepared by calcination at high temperature using complex oxide of $\mathrm{TiO}_{2}$ doped $\mathrm{La}_{2} \mathrm{O}_{3}$ as the supporter, and anion $\mathrm{S}_{2} \mathrm{O}_{8}^{2-}$ as the accelerant. The catalytic synthesis of $n$-butyl propanoate over STL was selected as the probe reaction to examine its catalytic esterification activity. The preparing conditions of STL were optimized via Taguchi method. The acidic structure, species and strength of STL were characterized by FTIR directly, FTIR spectrum of pyridine adsorbed on its surface and Hammett indicator, respectively. The esterification product was characterized by ${ }^{1} \mathrm{HNMR}$ and FTIR. The experimental results showed that the optimum preparation conditions were as follows: molar ratio of Ti to $\mathrm{La}$ at 5:1, $\left(\mathrm{NH}_{4}\right)_{2} \mathrm{~S}_{2} \mathrm{O}_{8}$ solution concentration of 2.0 $\mathrm{mol} \cdot \mathrm{L}^{-1}$ and calcination temperature of $500{ }^{\circ} \mathrm{C}$. STL belonged to the solid superacid $(\mathrm{Ho}=-13.75)$ with Brönsted acid sites. The esterification rate of above probe reaction could reach $99.3 \%$ at the reaction time of $90 \mathrm{~min}$.
\end{abstract}

\section{Introduction}

As an effective and eco-friendly heterogeneous catalyst, solid acid $\mathrm{SO}_{4}^{2-} / \mathrm{M}_{\mathrm{x}} \mathrm{O}_{\mathrm{y}}$ prepared by using transition metal oxide $\left(\mathrm{M}_{\mathrm{x}} \mathrm{O}_{\mathrm{y}}\right)$ and sulphuric acid as the supporter and accelerant, respectively, has been highly concerned by many scholars in the latest decades[1,2]. Compared with traditional liquid acids (e.g. $\mathrm{H}_{3} \mathrm{PO}_{4}, \mathrm{H}_{2} \mathrm{SO}_{4}$ ) as homogeneous catalyst, $\mathrm{SO}_{4}^{2-} / \mathrm{M}_{\mathrm{x}} \mathrm{O}_{\mathrm{y}}$ as the heterogeneous catalyst offers many advantages in chemical process, such as no corrosion to equipment, simple post treatment for reactions, high acidic strength and high catalytic activity[3,4]. Solid acid $\mathrm{SO}_{4}^{2-} / \mathrm{M}_{\mathrm{x}} \mathrm{O}_{\mathrm{y}}$ shows a great potential for application in biodiesel production[1,5] and many other catalytic reactions, such as esterification[6], alkylation[7], isomerization[8] and acetylation[9]. In recent years, there are some reports that transition metal oxide doped rare earth as the supporter of solid acid $\mathrm{SO}_{4}^{2-} / \mathrm{M}_{\mathrm{x}} \mathrm{O}_{\mathrm{y}}$ can significantly improve its catalytic properties in many reactions, such as selectivity, activity and thermal stability[10-12]. Anion $\mathrm{S}_{2} \mathrm{O}_{8}^{2-}$ can be employed as the accelerant to replace $\mathrm{SO}_{4}^{2-}$ for prepared $\mathrm{S}_{2} \mathrm{O}_{8}^{2-} / \mathrm{M}_{\mathrm{x}} \mathrm{O}_{\mathrm{y}}[13]$.

However, the titanium source for the preparation of $\mathrm{SO}_{4}^{2-} / \mathrm{M}_{\mathrm{x}} \mathrm{O}_{\mathrm{y}}$ containing $\mathrm{TiO}_{2}$ overwhelmingly was titanium tetrachloride or butyl titanate[11,12]. $\mathrm{S}_{2} \mathrm{O}_{8}^{2-2} / \mathrm{M}_{\mathrm{x}} \mathrm{O}_{\mathrm{y}}$ prepared by employing titanium sulfate, complex oxide of $\mathrm{TiO}_{2}$ doped $\mathrm{La}_{2} \mathrm{O}_{3}$ and anion $\mathrm{S}_{2} \mathrm{O}_{8}^{2-}$ as the titanium source, supporter and accelerant, respectively, has not been reported in the research field of solid acid yet. In our work, the precursor of complex oxide of $\mathrm{TiO}_{2}$ doped $\mathrm{La}_{2} \mathrm{O}_{3}$ was firstly prepared by a low-temperature deposition method with titanium sulfate as the titanium source; and then STL was prepared by calcinations at high temperature after the as-prepared precursor was impregnated by using $\left(\mathrm{NH}_{4}\right)_{2} \mathrm{~S}_{2} \mathrm{O}_{8}$ solution as the accelerant source; finally the acidic structure, species, strength and the catalytic esterification activity of STL were studied as well. 


\section{Experimental}

\subsection{Materials and Measurements}

All chemicals were commercial products of reagent grade. The infrared spectra were recorded on a Nicolet AVTATAR370 FTIR spectrophotometer with liquid membrane or $\mathrm{KBr}$ pellet in the 400 $4000 \mathrm{~cm}^{-1}$ region. ${ }^{1} \mathrm{HNMR}$ spectrum was recorded using Bruker AV $400 \mathrm{NMR}$ spectrometer, $\mathrm{CDCl}_{3}$ as solvent and tetramethylsilane as an internal standard.

\subsection{Preparation of STL}

STL was prepared mainly in three-step method as follows. Step 1: Certain amounts of titanium sulfate and lanthanum oxide were weighed according to the various molar ratios of Ti to La. The weighed lanthanum oxide was dissolved in sulfuric acid of $1.8 \mathrm{~mol} \cdot \mathrm{L}^{-1}$, stirred before the addition of the weighed titanium sulfate so as to obtain titanium sulfate solution containing 10 20 per cent of $\mathrm{La}_{2} \mathrm{O}_{3}$, and followed by the addition of $25 \%$ aqueous ammonia under vigorous stirring until the final $\mathrm{pH}$ of the solution was adjusted to $9 \sim 10$. The precipitate was further aged for $12 \mathrm{~h}$ in the mother liquid at $70{ }^{\circ} \mathrm{C}$, filtrated in a vacuum filtrator and washed by deionized water until no white precipitate was observed by dropping $0.1 \mathrm{~mol} \cdot \mathrm{L}^{-1} \mathrm{BaCl}_{2}$ solution into the mother liquid (i. e. without sulfate ion). The wet filter cake was dried at $110{ }^{\circ} \mathrm{C}$ till the constant weight was achieved before being crushed to a fine powder and passing the No. 60 100 sieve; by which the precursor of complex oxide of $\mathrm{TiO}_{2}$ doped $\mathrm{La}_{2} \mathrm{O}_{3}$ was prepared in this step. Step 2: The as-prepared precursor was impregnated with a certain concentration of ammonium peroxydisulfate solution (dosage of 15 $\mathrm{mL} \cdot \mathrm{g}^{-1}$ ), and filtrated by a vacuum pump again before dried at $110{ }^{\circ} \mathrm{C}$. Step 3: The resultant solid was calcined at a high temperature for $3 \mathrm{~h}$ and naturally cooled to room temperature. Finally, STL was obtained and stored in a dryer.

\subsection{Catalytic Esterification by STL}

Propionic acid $(0.1 \mathrm{~mol}), n$-butyl alcohol $(0.2 \mathrm{~mol})$ and STL $(1.5 \mathrm{~g})$ were introduced into a three-necked $200 \mathrm{~mL}$ round-bottomed flask equipped with a Dean-Stark trap, a magnetic stirrer and a condenser. The mixture was refluxed at the reaction temperature of $130 \sim 140^{\circ} \mathrm{C}$ while collecting water in the Dean-Stark trap. The refluxing was continued until visible water collection ended (about $90 \mathrm{~min}$ ). After cooling, the acid number of the mixture was measured, and the esterification rate $\left(E_{r}, \%\right)$ was calculated as (Equation 1$)[14]$ :

$$
E_{r}=\left[\left(A_{0}-A_{i}\right) / A_{0}\right] \times 100 \%
$$

Where $A_{0}$ is the initial acid number of reaction mixture, and $A_{i}$ is its final acid number. After the acid number measurement, the reaction mixture was firstly filtrated in vacuum to remove the catalyst; then washed successively with saturated sodium carbonate solution and deionized water; and finally dried by anhydrous sodium sulfate before distillation. The colorless liquid was obtained by collection of distilled fraction with b. p. $145-146{ }^{\circ} \mathrm{C}$. The purified product was analyzed by FTIR with liquid membrane.

\subsection{Characterization of STL}

The acidic structure and species of STL were respectively characterized by FTIR directly and non-in situ FTIR spectrum of pyridine adsorbed on its surface, because STL in the esterification was exposed to air and very little water from the esterified products. The process to examine the acidic species of STL was as follows. STL sample was activated at $300{ }^{\circ} \mathrm{C}$ for 3 h before cooling to room temperature, followed by exposed to the pyridine atmosphere for 3 days. STL adsorbed pyridine was baked in a vacuum at $80{ }^{\circ} \mathrm{C}$ until no pyridine was smelled before determined by FTIR with $\mathrm{KBr}$ pellet.

The acidic strength of STL can be determined by using Hammett indicators with different pKa values $\left(\mathrm{H}_{0}\right)[15]$. It was found that STL belonged to solid superacid after determined by Hammett indicator 2,4-dinitrotoluene $\left(\mathrm{H}_{0}=-13.75\right)$. 


\section{Results and Discussion}

\subsection{Optimization of Preparation Conditions for STL}

The preparation of STL mainly included three steps in which molar ratio of Ti to $\mathrm{La},\left(\mathrm{NH}_{4}\right)_{2} \mathrm{~S}_{2} \mathrm{O}_{8}$ solution concentration and calcination temperature were considered as the factors influencing esterification rate of the probe reaction[10]. The levels of the factors to be included for testing were chosen based on the conclusion of our earlier studies[16]. The recommended Taguchi orthogonal array was $L_{9}$ which is given in Table 1[17].

Table 1. Results of $\mathrm{L}_{9}\left(3^{3}\right)$ Orthogonal Array

\begin{tabular}{lllll}
\hline Trial No. & Ratio $^{\mathrm{a}}$ & Concen. $\left(\mathrm{mol} \cdot \mathrm{L}^{-1}\right)^{\mathrm{b}}$ & Temp. $\left.^{\mathrm{o}} \mathrm{C}\right)^{\mathrm{c}}$ & $\operatorname{Er}(\%)^{\mathrm{d}}$ \\
\hline 1 & $5: 1(1)$ & $1.5(1)$ & $400(1)$ & 97.3 \\
2 & $5: 1(1)$ & $1.8(2)$ & $500(2)$ & 97.9 \\
3 & $5: 1(1)$ & $2.0(3)$ & $600(3)$ & 86.5 \\
4 & $6: 1(2)$ & $1.5(1)$ & $500(2)$ & 99.3 \\
5 & $6: 1(2)$ & $1.8(2)$ & $600(3)$ & 54.8 \\
6 & $6: 1(2)$ & $2.0(3)$ & $400(1)$ & 95.6 \\
7 & $7: 1(3)$ & $1.5(1)$ & $600(3)$ & 60.2 \\
8 & $7: 1(3)$ & $1.8(2)$ & $400(1)$ & 97.3 \\
9 & $7: 1(3)$ & $2.0(3)$ & $500(2)$ & 95.7 \\
I(I/3) & $281.8(93.9)$ & $256.9(85.6)$ & $290.3(96.8)$ & \\
II(II/3) & $249.7(83.2)$ & $250.1(83.4)$ & $293.1(97.7)$ & \\
III(III/3) & $253.4(84.5)$ & $277.8(92.7)$ & $201.5(67.2)$ & \\
R & 10.7 & 9.3 & 30.5 & \\
\hline
\end{tabular}

Note. ${ }^{\mathrm{a}}$ Molar ratio of Ti to La; ${ }^{\mathrm{b}}\left(\mathrm{NH}_{4}\right)_{2} \mathrm{~S}_{2} \mathrm{O}_{8}$ solution concentration;

${ }^{\mathrm{c}}$ Calcination temperature; ${ }^{\mathrm{d}}$ Esterification rate of the probe reaction catalyzed by STL.

Among the three tested factors after analysis of the experimental results (Table 1), calcinations temperature contributed the highest influence on the esterification rate $(97.7 \%)$ and molar ratio of Ti to La showed a moderate influence (93.9\%). The concentration of $\left(\mathrm{NH}_{4}\right)_{2} \mathrm{~S}_{2} \mathrm{O}_{8}$ solution played a relatively less important role in influence on the esterification rate (92.7\%). The order in which individual factors affected the esterification rate was calcinations temperature $>$ molar ratio of Ti to $\mathrm{La}>$ concentration of $\left(\mathrm{NH}_{4}\right)_{2} \mathrm{~S}_{2} \mathrm{O}_{8}$. From Table 1, the optimum conditions for preparing STL were calcination temperature of $500{ }^{\circ} \mathrm{C},\left(\mathrm{NH}_{4}\right)_{2} \mathrm{~S}_{2} \mathrm{O}_{8}$ solution concentration of $2.0 \mathrm{~mol} \cdot \mathrm{L}^{-1}$, and molar ratio of $\mathrm{Ti}$ to $\mathrm{La}$ at 5:1.

\subsection{Acid Structure Analysis}

The infrared spectrum of STL prepared by the optimum condition is given in Figure 1.

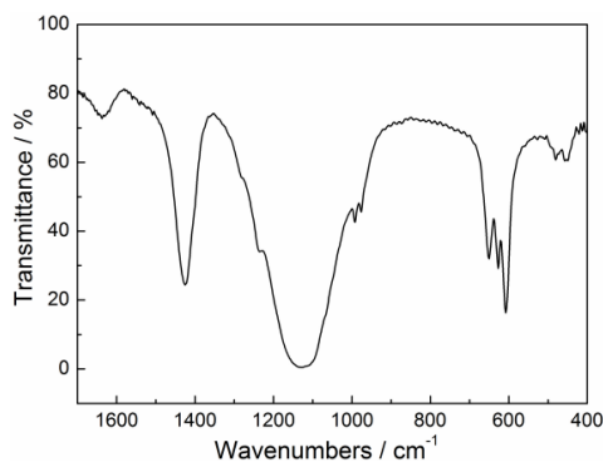

Figure 1. FTIR spectrum of the $1600-400 \mathrm{~cm}^{-1}$ region of STL

As shown in Figure 1, the infrared absorption peak at $1637 \mathrm{~cm}^{-1}$ is assigned to the deformation vibration mode of the adsorbed water[18]. The broad and strong absorption band near $1127 \mathrm{~cm}^{-1}$ 
represents the presence of more anatase $\mathrm{TiO}_{2}$, which indicates that more anion $\mathrm{S}_{2} \mathrm{O}_{8}^{2-}$ on the surface of STL combined with Ti metal atoms by double coordination bond, producing more acid for the increase of acidic amount. The peaks at 992 and $975 \mathrm{~cm}^{-1}$ are corresponded to the characteristics of the $\mathrm{S}-\mathrm{O}$ stretching vibration. The peaks observed at 1425 and $1283 \mathrm{~cm}^{-1}$ are assignable to the characteristics of asymmetric $\mathrm{S}=\mathrm{O}$ and antisymmetric $\mathrm{O}=\mathrm{S}=\mathrm{O}$ stretching vibration, respectively, which shows that anion $\mathrm{S}_{2} \mathrm{O}_{8}^{2-}$ support on $\mathrm{TiO}_{2}-\mathrm{La}_{2} \mathrm{O}_{3}$ coordinated to the metal $\mathrm{La}^{3+}$ and formed a bridged complex with double-structure[19]. The suction-induced complex $\mathrm{O}=\mathrm{S}=\mathrm{O}$ promoted the electron-accepting ability for the metal atoms (i.e. Lewis acid), which resulted in the formation of solid superacid. Compared with the infrared spectrum of $\mathrm{S}_{2} \mathrm{O}_{8}^{2-} / \mathrm{TiO}_{2}-\mathrm{EG}\left(\mathrm{TiO}_{2}\right.$-exfoliated graphite as the supporter) [20], the blue shift of the stretching vibration peak of $\mathrm{S}=\mathrm{O}$ band was observed from 1401 (in $\mathrm{S}_{2} \mathrm{O}_{8}^{2} / \mathrm{TiO}_{2}$-EG) to 1425 (in STL) $\mathrm{cm}^{-1}$, which indicates that the presence of $\mathrm{La}^{3+}$ cation can further strengthen double coordination bond between $\mathrm{S}=\mathrm{O}$ and metal atom. Therefore, doping a small amount of $\mathrm{La}_{2} \mathrm{O}_{3}$ into $\mathrm{TiO}_{2}$ as the supporter was beneficial to enhance the acidic strength of STL.

\subsection{Acid Species Analysis}

The acidic species of solid acid can be determined by FTIR spectrum of pyridine adsorbed on its surface[10]. It is well known that the peak at about $1540 \mathrm{~cm}^{-1}$ corresponds to pyridine adsorbed on the Brönsted acid sites, while the peak near $1450 \mathrm{~cm}^{-1}$ is ascribed to pyridine adsorbed on Lewis acid sites; the band around $1490 \mathrm{~cm}^{-1}$ is due to the vibrations of the H-bonded pyridine that involves the above two types of acid sites, and this band is characteristic of the total acidity of the material[10,21]. After the physisorbed pyridine was removed, non-in situ and in situ FTIR spectra of pyridine adsorbed on STL were recorded as given in Figure 2, in which in situ FTIR spectrum was obtained by self-made vacuum sample device.

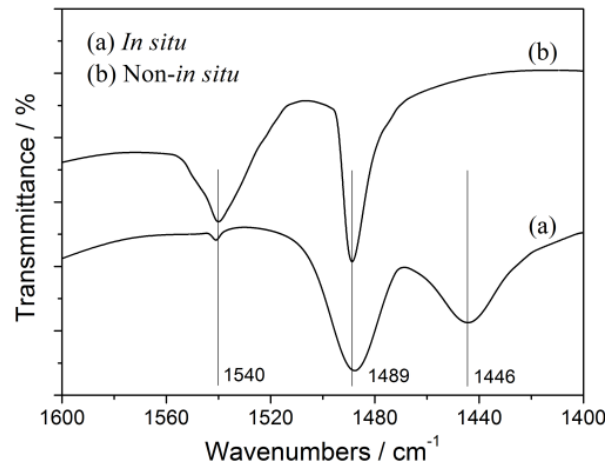

Figure 2. FTIR spectra of the $1600-1400 \mathrm{~cm}^{-1}$ region of pyridine adsorbed on STL

As shown in Figure 2, In situ pyridine FTIR spectrum (line a) indicates that Lewis acid sites were mainly formed on the surface of STL, while non-in situ pyridine FTIR spectrum (line b) indicates that STL belonged to Brönsted acid. This was attributed to the conversion of Lewis acid into Brönsted acid when STL was exposed to the water-vapor environment. Therefore, Brönsted acid sites on the surface of STL were the final active components for the catalytic esterification.

\section{4 ${ }^{1} \mathrm{H}$ NMR and FTIR Analysis of Esterification Product}

Proton NMR analysis of the esterification product catalyzed by STL is as follows: ${ }^{1} \mathrm{H}$ NMR $\left(\mathrm{CDCl}_{3}\right.$, $400 \mathrm{MH})$ ppm: $4.078\left(2 \mathrm{H}\right.$, in $\left.-\mathrm{CH}_{2}-\mathrm{O}-\right), 2.316\left(2 \mathrm{H}\right.$, in $\left.-\mathrm{CH}_{2}-\mathrm{C}=\mathrm{O}\right), 1.612\left(2 \mathrm{H}\right.$, in $-\mathrm{CH}_{2}$ - attached to methylenoxy $\left.-\mathrm{CH}_{2}-\mathrm{O}\right), 1.423\left(2 \mathrm{H}\right.$, in $-\mathrm{CH}_{2}$ - attached to groups $\left.-\left(\mathrm{CH}_{2}\right)_{2}-\mathrm{O}\right), 1.145\left(3 \mathrm{H}\right.$, in $\mathrm{CH}_{3}-$ attached to groups $\left.-\mathrm{CH}_{2}-\mathrm{C}=\mathrm{O}\right)$, and $0.942\left(3 \mathrm{H}\right.$, in $\mathrm{CH}_{3}$ - attached to groups $\left.-\left(\mathrm{CH}_{2}\right)_{3}-\mathrm{O}\right)$.

Additionally, FTIR spectrum of the above esterification product is showed as Figure 3. 


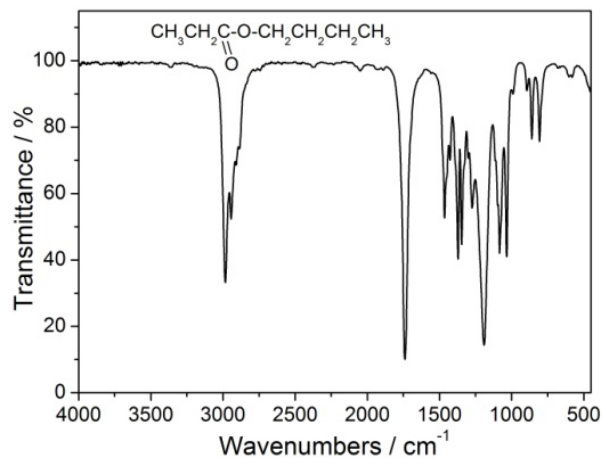

Figure 3. FTIR spectrum of the esterification product catalyzed by STL

Figure 3 shows that the peak observed at $2983 \mathrm{~cm}^{-1}$ is produced by the $-\mathrm{C}-\mathrm{H}$ stretching vibration in $-\mathrm{CH}_{3}$ attached to the saturated hydrocarbon groups. The peaks at 2943 and $2885 \mathrm{~cm}^{-1}$ are characteristic of the asymmetric and symmetric $-\mathrm{CH}_{2}$ stretches of the fatty hydrocarbon chains, respectively. The peak at $1740 \mathrm{~cm}^{-1}$ represents carbonyl $\mathrm{C}=\mathrm{O}$ stretching vibration of aliphatic ester, while the peak at $1190 \mathrm{~cm}^{-1}$ belongs to C-O-C stretch.

Based on the results of ${ }^{1} \mathrm{H}$ NMR and FTIR analysis, the molecular structure of the esterification product catalyzed by STL can be determined as in Figure 3. This indicates that the catalytic esterification between propionic acid and $n$-butyl alcohol occurred over solid acid STL.

\section{Conclusion}

By the employment of titanium sulfate, anion $\mathrm{S}_{2} \mathrm{O}_{8}^{2-}$ and complex oxide of $\mathrm{TiO}_{2}$ doped $\mathrm{La}_{2} \mathrm{O}_{3}$ as the titanium source, accelerant and supporter, respectively, the solid superacid STL with $\mathrm{H}_{0}=-13.75$ was prepared under the optimum condition as follows: molar ratio of Ti to $\mathrm{La}$ at 5:1, $\left(\mathrm{NH}_{4}\right)_{2} \mathrm{~S}_{2} \mathrm{O}_{8}$ solution concentration of $2.0 \mathrm{~mol} \cdot \mathrm{L}^{-1}$ and calcination temperature of $500{ }^{\circ} \mathrm{C}$. Brönsted acid sites were formed on the surface of STL whose acidic strength can be promoted by the addition of rare earth La. The esterification rate of $n$-butyl propanoate catalyzed by STL could reach $99.3 \%$ at 90 min reaction time. As an alternative to the traditional liquid acid, STL shows many advantages, such as excellent catalytic activity, no corrosion to equipment, water-resistant, high-temperature-resistant and simple post treatment with near zero waste-liquid discharge. However, more investigations need to be carried out on the process simplification for prepared STL, and the increase of its mechanical strength.

\section{Acknowledgments}

This research was financially supported by Key Research and Development Project of Hainan Province (ZDYF2016020), and Innovation and Entrepreneurship Training Project for College Students in Hainan Province (20140157).

\section{References}

[1]N. H. Embong, G. P. Maniam, M. H. A. Rahim, K. T. Lee and D. Huisingh, Utilization of palm fatty acid distillate in methyl esters preparation using $\mathrm{SO}_{4}^{2-} / \mathrm{TiO}_{2}-\mathrm{SiO}_{2}$ as a solid acid catalyst, $\mathrm{J}$. Clean. Prod. 116 (2016) 244-248.

[2]F. Lin, Z. X. Jiang, N. F. Tang, C. Zhang, Z. P. Chen, T. F. Liu and B. Dong, Photocatalytic oxidation of thiophene on $\mathrm{RuO}_{2} / \mathrm{SO}_{4}^{2-}-\mathrm{TiO}_{2}$ : Insights for cocatalyst and solid-acid, Appl. Catal. B 188 (2016) 253-258.

[3]J. C. Jiang, F. Gandara, Y. B. Zhang, K. Na, O. M. Yaghi and W. G. Klemperer, superacidity in sulfated metal-organic framework-808, J. Am. Chem. Soc. 136 (2014) 12844-12847. 
[4]A. K. Shah, M. Kumar, S. H. R. Abdi, R. I. Kureshy, N. H. Khan and H. C. Bajaj, Solvent-free aminolysis of aliphatic and aryloxy epoxides with sulfated zirconia as solid acid catalyst, Appl. Catal. A 486 (2014) 105-114.

[5]D. Rattanaphra, A. P. Harvey, A. Thanapimmetha and P. Srinophakun, Simultaneous transesterification and esterification for biodiesel production with and without a sulphated zirconia catalyst, Fuel 97 (2012) 467-475.

[6]G. D. Yadav and A. R. Yadav, Synthesis of ethyl levulinate as fuel additives using heterogeneous solid superacidic catalysts: Efficacy and kinetic modeling, Chem. Eng. J. 243 (2014) 556-563.

[7]G. D.Yadav and R. V. Sharma, Synthesis, characterization and applications of highly active and robust sulfated $\mathrm{Fe}-\mathrm{TiO}_{2}$ catalyst (ICT-3) with superior redox and acidic properties, J. Catal. 311 (2014) 121-128.

[8]N. Kamoun, M. K. Younes, A. Ghorbel, A. S. Mamede and A. Rives, Effect the solvent evacuation mode on the catalytic properties of nickel-modified sulfated zirconia catalysts: n-hexane isomerization, Reac. Kinet. Mech. Cat. 111 (2014) 199-213.

[9] K. J. Ratnam, R. Sudarshan Reddy, N. S. Sekhar, K.M. Lakshmi and F. Figueras, Sulphated zirconia catalyzed acylation of phenols, alcohols and amines under solvent free conditions, J. Mol. Catal. A 276 (2007) 230-234.

[10]R. Silva-Rodrigo, E. L. Cruz-Dominguez, F. E. Lugo-del Angel, J. Navarrete-Bolanos, R. Garcia-Alamilla, A. Olivas-Sarabia, J. A. Melo-Banda, L. C. Cruz-Netro, G. Zamora-Ramirez and A. Castillo-Mares, Studies of sulphated mixed oxides $\left(\mathrm{ZrO}_{2}-\mathrm{SO}_{4}^{2-}-\mathrm{La}_{2} \mathrm{O}_{3}\right)$ in the isomerization of n-hexane, Catal. Today 250 (2014) 197-208.

[11] L. Li, S. W. Liu, J. M. Xu, S. T. Yu, F. S. Liu and C. X. Xie, Esterification of itaconic acid using $\mathrm{Ln} \sim \mathrm{SO}_{4}^{2-} / \mathrm{TiO}_{2}-\mathrm{SiO}_{2}\left(\mathrm{Ln}=\mathrm{La}^{3+}, \mathrm{Ce}^{4+}, \mathrm{Sm}^{3+}\right)$ as catalysts, J. Mol. Catal. A 368 (2013) 24-30.

[12] H. L. Li, A. J. Deng, J. L. Ren, C. Y. Liu, W. J. Wang, F. Peng and R. C. Sun, A modified biphasic system for the dehydration of D-xylose into furfural using $\mathrm{SO}_{4}^{2-} / \mathrm{TiO}_{2}-\mathrm{ZrO}_{2} / \mathrm{La}^{3+}$ as a solid catalyst, Catal. Today 234 (2014) 251-256.

[13] J. X. Wang, H. Pan, L. Chen, D. W. Meng, X. L. Wu and Y. Q. Wang, Synthesis, characterization and catalytic properties of $\mathrm{S}_{2} \mathrm{O}_{8}^{2} / x w t \% \mathrm{Ce}-\mathrm{Al}-\mathrm{Fe}-\mathrm{O}$ solid acid catalysts in the esterification reaction of acetic acid with $n$-butanol, Reac. Kinet. Mech. Cat. 113 (2014) 407-416.

[14] F. L. Pua, Z. Fang, S. Zakaria, F. Guo and C. H. Chia, Direct production of biodiesel from high-acid value Jatropha oil with solid acid catalyst derived from lignin, Biotechnol. Biofuels 4 (2011) 56-63.

[15] D. Fraenkel, N. R. Jentzsch, C. A. Starr and P. V. Nikrad, Acid strength of solids probed by catalytic isobutane conversion, J. Catal. 274 (2010) 29-51.

[16] D. Z. Liao and J. Y. He, A study on catalytic performance of a new solid acid $\mathrm{SO}_{4}^{2-}-\mathrm{M}_{\mathrm{O}} \mathrm{O}_{3}-\mathrm{TiO}_{2}$ in preparation of n-butyl propanoate, Chin. J. Org. Chem. 21 (2001) 1153-1156 (In Chinese).

[17] P. J. Rose, Taguchi Techniques for Quality Engineering, McGraw-Hill Book Company, New York, 1988.

[18]Y. H. Wang, S. X. Dong and G. Z. Lu, Structure and catalytic properties of $\mathrm{SO}_{4}^{2-} / \mathrm{ZrO}_{2}$ catalyst modified by different rare earth compounds, Chin. J. Inorg. Chem. 23 (2007) 677-682 (In Chinese).

[19] J. R. Sohn, S. H. Lee and J. S. Lim, New solid superacid catalyst prepared by doping $\mathrm{ZrO}_{2}$ with Ce and modifying with sulfate and its catalytic activity for acid catalysis, Catal. Today 116 (2006) 143-150. 
[20]Q. Zhao, S. M. Meng, J. Wang, Z. P. Li, J. H. Liu and Y. Guo, Preparation of solid superacid $\mathrm{S}_{2} \mathrm{O}_{8}^{2-} / \mathrm{TiO}_{2}$-exfoliated graphite (EG) and its catalytic performance, Ceram. Int. 40 (2014) 16183-16187.

[21] D. J. Rosenberg and J. A. Anderson, On the environment of the active sites in phosphate modified silica-zirconia acid catalysts, Catal. Lett. 94 (2004) 109-113. 